\title{
Archiv
}

Magdeleine Marx

\section{Die neuen russischen Frauen 1923}

\section{(Abdruck aus »Die Frauen im Staat «)}

Die französische Schriftstellerin Magdeleine Marx ist in Rußland gewesen. Sie läßt in der in New York erscheinenden Zeitschrift "The Nation « eine Reihe von Artikeln erscheinen, in denen sie die Eindrücke niederlegt, die sie von den russischen Frauen empfangen hat.

Bei den sich widersprechenden Gerüchten, die heute in Deutschland über Sowjet-RuBland verbreitet werden, ist es von höchstem Interesse zu erfahren, was eine Frau wie Magdeleine Marx über die Frauen im heutigen Rußland schreibt. Sie betitelt ihren ersten Artikel: »Die Arbeiterin« und führt aus:

»Häufig habe ich mir gelobt, niemals den Fehler zu begehen, Frauen von diesem oder jenem Lande zu beschreiben. Nichts irritiert so stark wie die Verallgemeinerung von französischen Frauen als Weibchen, von deutschen als sentimentale Gretchen, von englischen als blonde, kalte Mannweiber; oder wenn man die amerikanischen Frauen durch drei Symbole kennzeichnet, nämlich: Tennisspiel, Diamanten und Milliardärgatte. Und dennoch ...

Ich bin in Rußland, dem Lande der Bären, Renntiere und Tiger, dem Lande der tropischen Blumen und eisigen Kälte, der arktischen und orientalischen Völker, dem Lande der Unendlichkeit. In den Straßen von Sebastopol begegnen mir prächtige Mädchen mit emailschwarzen Augen und schlanken Gliedern, die den Mädchen Südfrankreichs ähneln. An der Küste von Batum bewundere ich in tropischer Alpenlandschaft nackte, herrliche, bronzene Gestalten in der Sonne liegend. In dem kalten Schatten der Bazare von Tiflis schreiten die Mädchen Georgiens wie die Prinzessin aus >Tausend und eine Nachte. In Aserbeidschan tinde ich die flüchtigen Schatten der Frauen in schwarzem Charchaf. Ich begegne den Abkommen der Kirkisen und Tscherkessen, den sibirischen Bäuerinnen mit dem scheuen Blick und den mongolischen Backen, den liliengleichen Mädchen von Archangelsk mit den distelblauen Augen und dem blonden Haar. 
Monate vergehen. Ich lebe das tägliche Leben in Sowjet-RuBland. Und langsam komme ich zu der Überzeugung, daß das, was falsch und oberflächlich in anderen Ländern ist, in diesem Lande unter neuem sozialem System verschwindet, welches das Leben aller Frauen beeinflußt, es gibt ihnen die Möglichkeit voller Freiheit, es gibt ihnen neue Vorrechte, neue Verpflichtungen, es erfüllt alle mit einem neuen Geist.

Bei der völligen Umänderung aller Lehensgewohnheiten, was ist aus der Arbeiterin, der Bäuerin, der intellektuellen Frau geworden, die in ihrer Jugend nur die Gefängnismauern kannte? Was denkt die Prinzessin, die noch vor kurzer Zeit unter der dreifachen Knute von Rang, Etikette und Gatte Rußland zum Tummelplatz ihrer Liebesreize und Launen machte.

Um die Frauen aller Klassen zu verstehen, ist es unerläßlich, sich mit den neuen Ehegesetzen in Sowjet-Rußland bekanntzumachen. Vor der Revolution kannte man nur die kirchliche Trauung. Heute ist nur die Zivilehe gesetzlich. Nichts ist leichter und einfacher als die Ehevorschriften: eine einfache Erklärung von beiden Seiten. Die weitgehendste Freiheit ist beiden Teilen zugesichert: Wenn ein Gatte den Wohnsitz ändert, so ist der andere nicht gezwungen, ihm zu folgen. Heirat setzt nicht Gütergemeinschaft voraus. Und gegenseitige Sicherheit ist gewährt. Der bedürftige Teil, Mann oder Frau, hat Anspruch auf die Unterstützung des anderen, wenn dieser dazu im Stande ist. Vater und Mutter teilen die Rechte über ihre Kinder. Beides, das Eingehen der Ehe und die Scheidung, sind ein einfacher Akt der Formalität. Scheidung erfolgt auf gegenseitige Übereinstimmung oder auf Wunsch eines Teiles der Gatten. Da es aber Frauen gibt, die es überhaupt ablehnen, eine Ehe einzugehen, so nimmt sich das Gesetz ihrer im Falle der Mutterschaft an und macht den Vater in gleicher Weise verantwortich für die Sorge um die Kinder.

Ist es nicht klar, daß diese Umgestaltung der Verhältnisse einen neuen Typus von Frauen entwickelte? Das erkennend, finden wir nicht verallgemeinert sdie russische Frau<, aber vielleicht eine geistige Einstellung, welche sowohl der Arbeiterin, der Bäuern, der Intellektucllen wie den Frauen der alten Aristokratic und der neuen Bürgersfrau eigen ist.

Es ist Winter. Ich hesuche die Goujou-Fabrik, eine Metallfabrik in der Umgebung von Moskau. In der Essenspause sitze ich unter den Arbeiterinnen, sie bieten mir freundlich Tee an und beantworten mir lachend meine auf Russisch im schauerlich französischen Akzent gestellten Fragen: > Wie lang ist die Arbeitszeit? Acht Stunden wie überall, von 8 Uhr früh bis 5 Uhr nachmittags mit einer Essenspause von einer Stunde. Mädchen von 16 bis 18 Jahren arbeiten 6 Stunden.

Was wird verdient? Die Löhne werden von einer Kommission, bestehend aus Arbeitgebern und Arbeitnehmern, festgesetzt. Männer und Frauen erhalten gleiche Löhne. In der Goujou-Fabrik belaufen sich die Löhne monatlich auf 120-160 Millionen Rubel. Das ist nicht viel, es reicht aus, um die laufenden Ausgaben des Lebens zu bestreiten, aber es ist nicht genug, um den gesamten Lebensunterhalt zu sichern.<

In der Fabrik befindet sich ein Kinderheim, wo die Arbeiterinnen ihre kleinen Kinder unterbringen und stillen können. Eine der Arheiterinnen, Natascha, zeigt mir das Heim und ihr Kind, sie erzählt mir von der glänzenden Fürsorge, die 
Sowjet-Rußland für sie vor, während und nach der Geburt - die unsagbar schwer war - gehabt hat.

Wir kehren zu den Arbeiterinnen zurück, sie zeigen mir ihre Zeitung, betitelt: ,Die Arbeiterin`, und erzählen mir von ihrem einfachen Leben. Natascha ist nicht unglücklich, sie ist mit einem Manne verheiratet, der nachts in den Hochöfen arbeitet und 300 Millionen Rubel im Monat verdient. Sie leben in der Nähe ihrer Arbeitsstätte und haben für sich und vier Kinder zwei Zimmer. Wenn sie abends heimkommt, kocht sie den Tee; Brot, Eier und Käse dazu bilden ihr Mittagsmahl. Sie erzählt mir von ihren Vergnügungen, die im Besuch von Theatern, Museen und in Vorträgen zur Vervollkommnung ihrer Bildung bestehen.

SchlieBlich stelle ich die Frage, die mir schon lange auf den Lippen brennt und mit der ich immer zurückgehalten habe: Welchen Anteil nehmen die Frauen an der Politik und was denken sie vom heutigen Rußland? Erstaunte Gesichter starren mich an. 'Wie kann man eine solche Frage stellen? Gibt es wirklich Fremde, die glauben, das russische Volk verlange nach einer anderen Regierungsform als der herrschenden.< Dieses Mal ist es eine alte Frau, die spricht, die mit ihren gelben, abgearbeiteten Händen lebhaft gestikuliert. 'Sie sehen, wir leben nicht wie hochadlige Herren und Damen, aber wir fühlen uns jetzt doch als Menschen, früher wurden wir schlechter behandelt als das liebe Vieh. Ach! Ich begreife, Sie haben ja keine Ahnung, wie es uns früher erging. Ich konnte nicht lesen, man hat es mich jetzt gelehrt. Man legt uns die politischen Dinge klar, und wir verstehen sie. Aber was spreche ich denn von mir, ich zähle nicht mehr mit, ich bin ja alt, aber ich habe drei Töchter. Marie, ich sah sie seit dem Sommer nicht, sie wurde immer kränker, blässer und schwächer, deshalb schickte man sie aufs Land. Unter der zaristischen Regierung wäre Marie längst gestorben. Jetzt arbeitet sie in einer Petersburger Töpferei und wird sich bald verheiraten. Meine andere Tochter Vera studiert im Institut in Pokrovsky. Ihr sehnlichster Wunsch, Kinderärztin zu werden, wurde ihr erfüllt. Ehedem wäre so etwas unmöglich gewesen ... «

Magdeleine Marx führt zum Schluß ihres Artikels aus:

»Um der Wahrheit willen muß ich gestehen, daß nach tausenden Beweisen, die mir die Arbeiterinnen gaben, ich den Eindruck gewonnen habe, daß die russische Arbeiterin dem jetzigen Regierungssystem mit ganzer Seele ergeben ist und daß sie in der Mehrheit stark revolutionär ist.

An meinem geistigen Auge zieht jener endlose Zug von Arbeiterinnen am fünften Jahrestag der Sowjet-Republik vorüber. Ich sehe sie wieder, Arm in Arm einen weiten Strom bildend, mit scharlachroten Kopftüchern auf dem , Roten Platz $<$. Ich höre ihre Lieder und frohen Ausrufe. Ich sehe ihre glänzenden Augen, als sie an der Tribüne vorüberziehen, auf der Trotzky stand ...

Einige Tage vorher hatte ich eine Arbeiterin besucht, die ein bescheidenes Zimmer im Kreml bewohnt. Sie nimmt eine hervorragende Stellung in der Kommunistischen Partei ein. In sich geschlossen, ernst, führt sie das Leben einer Asketin, sie schläft nur vier Stunden, sie ist der vollkommene Typus der Arbeiterin, die zur kommunistischen Führerin geworden ist. Sie ist dreißig Jahre alt und mit einem Soldaten verheiratet. Sie war zwölf Jahre in New Yorker Geschäften tätig und hat in ihrer Haltung etwas von den amerikanischen Frauen angenommen. Ihre Worte kehrten mir zurück, als ich jene Fabrik in Moskau verlieB: ,Sie sehen, 
vom materialistischen Standpunkt aus betrachtet, führen unsere Arbeiterinnen ein kärglicheres Leben als die französischen; sie sind nicht so gut ernährt, sie wohnen weniger gut, sie sind ärmlicher gekleidet als die amerikanischen Arbeiterinnen. Aber Sie müssen begreifen, daß ihre heutige Lebenshaltung einen ungeheuren Fortschritt bedeutet, verglichen mit der entsetzlichen Armut der Vergangenheit. Und vom geistigen Gesichtspunkt aus betrachtet, soweit die Freiheit und Menschenwürde mitspricht, soweit der Glaube an die Zukunft beteiligt ist, so scheint es, als ob ein ganzes Jahrhundert übersprungen wäre. Und dann<, fügte sie lächelnd hinzu, indem sie den Dampf ihrer Zigarette beobachtete, sunser Land ist wohl das einzige, wo Frauenbewegung keine Existenzberechtigung hat. Es mag noch vieles zu tun übrig bleiben, was die Zeit allein ordnen kann, aber eine Angelegenheit ist endgült geregelt, und das ist die Befreiung der Frauc.«

Aus: "Die Frau im Staat«, Hrsg. v. A. Augspurg/L. G. Heymann, Nr. 12, 1923, S. 3-5. 


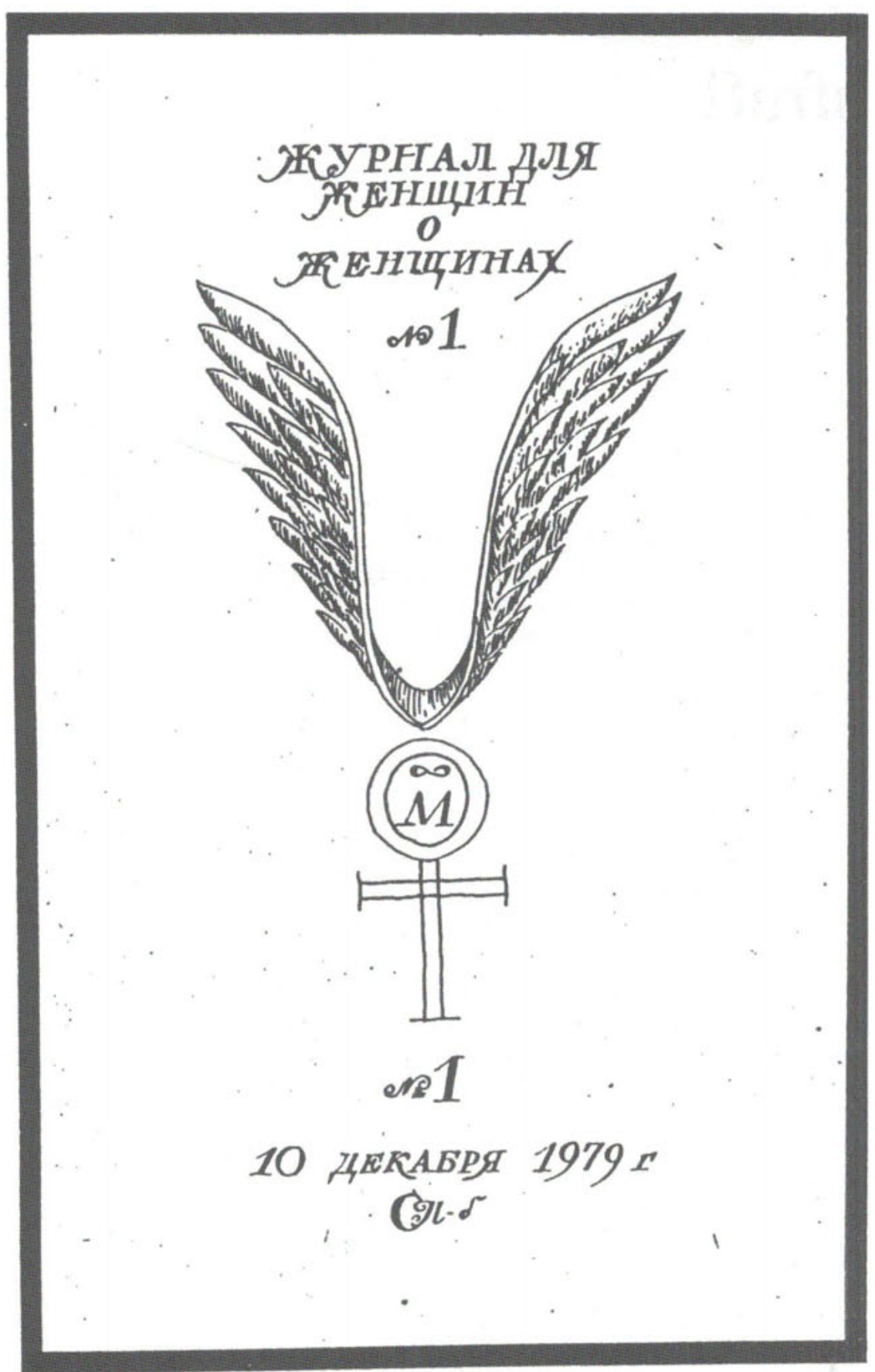

[)as Titelblatt des ersten Frauenalmanch der Leningrader Frauen von 1979 


\section{Die »Leningraderinnen" Aufruf!}

\section{Liebe Schwestern!}

Kaum ins Leben getreten, spüren wir, daß seine ganze Last unseren Schultern vorbehalten ist. Am Anfang scheint all das, was uns - in einem dichten Ring umgebend - beleidigt und verletzt, irgendwie zufällig. Es ist unmöglich, daran zu glauben, daß das Leben völlig unschuldige Menschen dafür bestrafen kann, daß sie als Frauen geboren sind. Jegliches Leiden erscheint der Menschheit unzulässig. seine sofortige Ausrottung erforderlich - ausgenommen das Leiden der Frauen. Unsere Lage ist so unerträglich, daß sie von selbst verschwinden müßte, sich auflösen wie ein nächtlicher Alptraum. Jedoch von selbst ändert sich üherhaupt nichts. Und wir sind überzeugt davon, daß niemand uns hilft - außer wir selbst. Nur, wenn wir uns zusammenschließen, unsere Leiden und unsere Bitterkeit besprechen; nur, wenn wir unsere Erfahrungen uns bewußt machen und verallgemeinern, können wir einen Ausweg finden; können wir uns selbst und tausenden Frauen, die genauso leiden wie wir, helfen.

Genau deswegen haben wir uns entschlossen, das erste - in unserem Lande freie - Journal für Frauen herauszugeben. Auf den Seiten dieser Zcitschrift herichten wir über die Lage der Frau in der Familie, bei der Arbeit, im Krankenhaus, in der Geburtsstation, üher die Lage unserer Kinder, üher den Stand der theoretischen Reflexion.

Wir werden künstlerische und publizistische Werke von Frauen veröffentlichen. Wir werden konkret von Schicksalen unserer Zeitgenossinnen erzählen. Wir bitten Sie: Schreiben Sie uns über alles, was Sie aufregt und bewegt. Schicken Sie uns ihre Werke, Erzählungen über Ihre Schwestern, Mütter und Freundinnen. Falls es notwendig sein sollte, fahren die Korrespondentinnen unserer Zeitung zu Ihnen, um so gut als möglich zu helfen.

Wir hoffen, daß wir uns mit vereinten Kräften in Bewegung setzen werden und mit uns die Befreiung der Frauen.

"Wenn das, was verborgen war, offenhar wird, wird es hell.«

(Aus: Die Frau in Rußland - Almanach Nr. 1, 1979) 